\title{
Credits, Crises, and Capital Controls: A Microeconomic Analysis*
}

\author{
Zvika Neeman ${ }^{\dagger}$ and Gerhard O. Orosel ${ }^{\ddagger}$
}

January 26, 2000

\begin{abstract}
We analyze the behavior of foreign banks who sequentially provide credit to finance projects in an emerging market. The foreign banks are exposed to both micro-economic risks and the macro-economic risk of a currency crisis, and there are no bailout guarantees. Nevertheless, we show that it is often the case that banks provide too much credit too easily and that this behavior may precipitate the onset of a currency crisis. We demonstrate how the imposition of capital controls in the form of taxes and subsidies on foreign investment may improve the situation.
\end{abstract}

Jel Classification numbers: D82, D83, F32, F34, O16.

KEYWORDS: emerging markets, foreign credit, currency crisis, capital controls.

\footnotetext{
* Acknowledgements to be added.

$\dagger$ Department of Economics, Boston University, 270 Bay State Road, Boston, MA 02215. Email zvika@BU. edu; WWW http://econ.bu.edu/neeman/.

* Department of Economics, University of Vienna, Hohenstaufengasse 9, A-1010, Vienna, Austria. Email gerhard.orosel@univie.ac.at. Currently (until July 2000) at: Weatherhead Center for International Affairs, Harvard University, 1737 Cambridge Street \#410, Cambridge, MA 02138, Email gorosel@cfia.harvard.edu
} 


\section{Introduction}

Recent years have repeatedly witnessed a type of international economic crisis that is often referred to as a "currency crisis": the "Tequila crisis" in 1994-5, the "Asian crisis" in 1997, the "Russian crisis" in 1998, and the Latin American crisis in 1999. ${ }^{1,2}$ In spite of their ominous name, such international economic crises do not seem to be particularly rare or unique events. They all commonly require the presence of three essential "ingredients": a debtor country, foreign creditors, and credits that are denominated in some international currency, such as US dollars. While it is doubtless the case that it is the interaction among these three factors that precipitates international currency crises, in this paper we confine our analysis to the issue of the behavior of foreign creditors.

Specifically, we focus our attention on the behavior of foreign banks and on the consequences of three interrelated stylized facts. First, there is the phenomenon of herding, by which we refer to a situation where foreign banks flock to a few identical global "hot spots," such as emerging markets in Southeast Asia. Second, when a currency crisis occurs, no creditor enjoys priority in access to the country's international reserves. Finally, third, due to the presence of fixed costs, and perhaps for other reasons too, the competition among the foreign banks is imperfect. Consequently, there are (excess) expected profits to be made and thus there is "competition for clients" among the foreign banks.

We consider a model where foreign banks finance local long-term projects by short-term credits that are denominated in foreign currency. The foreign banks face two kinds of risk: the "macro-economic" risk of a currency crisis, and the "micro-economic" risk of project failure. We assume that the foreign banks move sequentially, obtain a private signal about the micro risk associated with the projects they consider financing, and observe the actions of all previous foreign banks. We analyze the equilibrium of this model and show that it is generally inefficient. In particular, for a wide range of parameter values, foreign banks provide too many credits too easily and thus generate an inefficiently high risk of a currency crisis. For other parameter values, they inefficiently provide no credits at all. We demonstrate how

\footnotetext{
${ }^{1}$ Often, the sharp fall in the value of the local currency is the consequence rather than the cause of the crisis, although in itself, the decline in the value of the local currency may contribute, sometimes dramatically, to further deterioration.

${ }^{2}$ Lindgren, Garcia, and Saal (1996, p. 20) for example count as many as eighty to a hundred crises over the past quarter century.
} 
the imposition of capital controls through taxes and subsidies on short-term foreign credit can improve the situation.

In contrast to other papers on currency crises, we concentrate on the foreign banks' incentives for providing credit rather than on their incentives to withdraw the credit provided once a crisis is anticipated. Neither do we consider the issue of the viability of the financial institutions in the debtor country, nor anything else concerning the debtor country's behavior. Finally, we do not assume that foreign banks enjoy bailout guarantees. ${ }^{3}$

The results of our analysis have some implications with respect to the present debate among economists and politicians about the costs and benefits of "globalization," at least in as much as globalization is interpreted as implying the relaxation of constraints on short-term capital inflows. We describe a clearly identified set of situations where imposing controls on short-term capital inflows can well prove to be beneficial. ${ }^{4}$

The analysis proceeds as follows. In the next section, we present the theoretical model. In Section 3 we examine equilibrium behavior, and in Section 4 we study its efficiency properties. In Section 5 we show that an informed reliance on taxes and subsidies can increase efficiency and even achieve the second-best, or at least an appropriately defined "third-best" outcome. We offer some conclusions in Section 6. All proofs are relegated to the Appendix.

\section{The Model}

We consider a hypothetical "emerging market," and a countably infinite number of ex-ante identical foreign banks. Each foreign bank is able to provide $C$ standardized short-term credits that are denominated in some "international currency." The exchange rate between

\footnotetext{
${ }^{3}$ Schneider and Tornell (1999), for example, distinguish between two classes of models in the literature on currency crises. One that assumes the existence of government bailout guarantees and focuses its attention on the implied moral hazard problem for the foreign banks, and the other which involves the existence of "multiple equilibria based on illiquidity." (p. 4). Additional references are provided therein. See also Chang and Velasco (1999), Furman and Stiglitz (1998), and Sachs et al. (1996).

${ }^{4}$ Krugman (1999), for example, writes "my own suggestion is that governments actively try to discourage local companies from borrowing in foreign currencies, and also perhaps from relying too much on borrowed funds in general (that is, reduce their "leverage"). The best way to do this is probably by taxing companies that borrow in foreign currency." (p. 165). This position is shared by Stiglitz (1999) who has been widely quoted on the subject in the popular press (see, e.g. Louis Uchitelle's article in The New York Times, December 2, 1999).
} 
the emerging market's local currency and the international currency is assumed to be fixed, provided of course that no currency crisis has occurred. We assume that the emerging market has within it $2 C$ "investment opportunities" or projects, each of which is in need of one standardized credit. ${ }^{5,6}$ For the purposes of our discussion, it does not matter whether the foreign banks provide these projects with direct financing, or whether financing is provided via domestic local banks. We normalize the foreign banks' opportunity costs of capital to zero, so that they will want to finance local projects if and only if they yield a positive expected return. ${ }^{7}$ Below, we sometimes refer to the act of providing credit by a bank as investment.

There are three stages, the first of which is divided into a large number of short periods denoted by $t \in\{1,2, \ldots\}$. The game starts at the first stage. The foreign banks move sequentially, inspect projects within the country, and decide about whether or not to provide short-term credit. The credits are short-term in the sense that they are due at the second stage, but the projects can only be completed at the third stage. ${ }^{8}$ In the second stage, there is a certain probability that a currency crisis occurs. We assume that, all else equal, this probability is increasing with the number of credits that were provided in the first stage. ${ }^{9} \mathrm{~A}$

\footnotetext{
${ }^{5}$ The assumption that the number of investment opportunities is $2 C$, and hence the number of credits given is less or equal to $2 C$ is a simplified version of the assumption that there is a finite number of investment opportunities in which foreign banks may possibly may be interested. We interpret $C$ as "a few," and $2 C$ as "many" credits. Extending the model to include the case where the number of investment opportunities is $k C$ for some $k>2$, is cumbersome and does not generate significant additional insights.

${ }^{6}$ An additional reason for why not more than $2 C$ credits may be provided is the presence of negative payoff externalities. As will become clearer below, the provision of credit increases the probability of a currency crisis thereby reducing the expected profit made on all credits provided.

${ }^{7}$ Notice that a positive expected return is sufficient fo investment but not necessary. We assume however that a bank does not invest if its expected payoff is equal to zero. Our results do not depend on this tie-breaking assumption.

${ }^{8}$ We do not analyze the reason for why banks provide only short-term as opposed to long-term credit. One reason may be incomplete contracting. For example, foreign banks may not be able to control the riskiness of the project or the effort level of the debtor, but may be able to observe the debtor's effort choice after a short period. A bank can prevent the debtor from choosing too risky projects or a low level of effort by conditioning the renewal of the short-term credit upon satisfactory performance. Another reason may be the bank's own liquidity needs. Whatever the reason, we note that it is often the case that banks finance long-term projects through short-term credits in practice.

${ }^{9}$ Recent empirical work (see, e.g., Chang and Velasco (1998), Furman and Stiglitz (1999), Kaminsky et al. (1998), Rodrik and Velasco (1999) and Tornell (1999)) presents evidence that is consistent with the
} 
currency crisis causes those projects that are financed by the foreign banks to be terminated at a great loss to the foreign banks. If a currency crisis does not occur, the short-term credits are renewed, and the game proceeds into the third stage. In the third stage, the projects are completed and the foreign banks receive a payment that is positively related to the projects' success.

A state of the world $\omega=(\theta, \lambda) \in\left\{\theta_{1}, \theta_{2}, \theta_{3}\right\} \times\left\{\lambda_{L}, \lambda_{H}\right\}=\Omega$ is thus assumed to consist of a "macro-component" $\theta \in\left\{\theta_{1}, \theta_{2}, \theta_{3}\right\}$ and a "micro-component" $\lambda \in\left\{\lambda_{L}, \lambda_{H}\right\}$. A commonly known prior distribution $\operatorname{Pr}(\omega)$ describes the probability of the various states of the world. We assume that $\theta$ and $\lambda$ are independent, that is $\operatorname{Pr}(\omega)=\operatorname{Pr}(\theta) \operatorname{Pr}(\lambda)$ for every $\omega \in \Omega$. The macro-component $\theta$ captures the risk of a currency crisis (which may depend on the total number of short-term credits provided by the banks), whereas the micro-component $\lambda$ captures the risk of project failure. We impose the following additional structure: When $\theta=\theta_{1}$, a currency crisis occurs if and only if the foreign banks have provided a total of at least $C$ credits. When $\theta=\theta_{2}$, a currency crisis occurs if and only if the foreign banks have provided a total of (at least) $2 C$ credits. When $\theta=\theta_{3}$, a currency crisis does not occur, regardless of the total number of credits provided by the foreign banks. Thus, $\theta_{1}$ is interpreted as a "bad" state where the provision of even a "few" credits triggers a crisis; $\theta_{2}$ is interpreted as a "mediocre" state where only the provision of "many" credits triggers a crisis; and $\theta_{3}$ is interpreted as a "good" state where even if many credits are provided, no crisis occurs. The micro-component $\lambda$ is related to the projects' success. We assume that conditional on $\lambda$, all projects have the same probability of being successful, and interpret $\lambda=\lambda_{L}$ as indicative of a low probability of success, and $\lambda=\lambda_{H}$ as indicative of a high probability of success. The implied correlation among the projects' likelihood of success is motivated by the fact that projects' success is likely to be significantly positively correlated in the type of environments we consider. ${ }^{10}$ To summarize, we are interested in the three following events: (1) a currency crisis occurs, ${ }^{11}$ (2) a currency crisis does not occur, but hypothesis that a currency crisis is triggered by a country's foreign reserves becoming sufficiently low relative to its foreign currency denominated debt. See Morris and Shin (1998) for a theoretical model where this can be reproduced as the unique equilibrium outcome.

${ }^{10}$ Consider for example the case of investments in holiday resort projects in Southeast Asia. The success of such projects is highly correlated because it depends on common geographic and cultural characteristics, as well as on other common variables that determine whether the country where the resorts are located becomes an attractive international tourist destination.

${ }^{11}$ That is, when either $\theta=\theta_{1}$ and $C$ credits have been provided, or $\theta \in\left\{\theta_{1}, \theta_{2}\right\}$ and $2 C$ credits have been 
the projects mostly fail, ${ }^{12}$ and (3) a currency crisis does not occur, and the projects mostly succeed. ${ }^{13}$

We assume that before a bank decides whether or not to provide credit, it "inspects" the projects and obtains a private signal about their micro-risk. The public nature of macrorisks implies that all foreign banks are equally informed about them, and have expectations that are given by the prior distribution. A foreign bank's private signal $s \in\left\{s_{L}, s_{U}, s_{H}\right\}$, $s_{L}<s_{U}<s_{H}$, can either be low and indicative of project failure, $s=s_{L}$, high and indicative of project success, $s=s_{H}$, or be uninformative, $s=s_{U}$, which is equivalent to getting no signal at all. More specifically, letting $\operatorname{Pr}(s \mid \lambda)$ denote the probability that a foreign bank observes the signal $s$ when the state of the world is $\lambda$, we assume that $\operatorname{Pr}\left(s_{L} \mid \lambda_{L}\right)=$ $\operatorname{Pr}\left(s_{H} \mid \lambda_{H}\right)>\operatorname{Pr}\left(s_{L} \mid \lambda_{H}\right)=\operatorname{Pr}\left(s_{H} \mid \lambda_{L}\right) \geq 0$, and $\operatorname{Pr}\left(s_{U} \mid \lambda_{L}\right)=\operatorname{Pr}\left(s_{U} \mid \lambda_{H}\right) \geq 0$. That is, the distribution that relates the private signals to the state of the world is symmetric so that good and bad signals "cancel" each other and are together equivalent to the uninformative signal.

Recall that the first stage of the game is divided into a large number of short periods $t \in\{1,2, \ldots\}$. In every such period $t$, one randomly selected foreign bank (bank $t$ ) observes projects within the country, obtains a private signal, denoted $s_{t}$, about their chances of success, and decides whether or not to provide credit ("invest"). We denote the actions of the foreign banks by $a \in\{0,1\}$, where $a=0$ means that a bank declines to provide any credits, and $a=1$ means that a bank provides $C$ credits. The action of the bank that moves at time $t \in\{1,2, \ldots\}$ is denoted $a_{t}$. The bank that moves at time $t$ observes the actions of all the banks that moved before it in periods $\{1, \ldots, t-1\}$, but not their signals. Thus, the information that is available to bank $t$ consists of its own private signal $s_{t}$ and the history of actions $h_{t-1}=\left\{a_{1}, \ldots, a_{t-1}\right\}$. We assume that this process continues as long as the country has not yet received $2 C$ credits, and banks are still willing to provide credit if they observe a favorable enough signal. The first stage of the game ends when either of these two requirements stops being satisfied any longer.

Foreign banks' preferences are described as follows: A bank that does not provide any provided.

${ }^{12}$ That is, when either $\theta \in\left\{\theta_{2}, \theta_{3}\right\}, C$ credits are provided, and $\lambda=\lambda_{L}$, or $\theta=\theta_{3}, 2 C$ credits are provided, and $\lambda=\lambda_{L}$.

${ }^{13}$ That is, when either $\theta \in\left\{\theta_{2}, \theta_{3}\right\}, C$ credits are provided, and $\lambda=\lambda_{H}$, or $\theta=\theta_{3}, 2 C$ credits are provided, and $\lambda=\lambda_{H}$. 
credit enjoys a payoff of zero in every state of the world. The payoff of a foreign bank that has provided $C$ credits depends on the state of the world, and on the total number of credits that have been provided by the end of the first stage of the game, which we denote by $\gamma \in\{0, C, 2 C\}$. It is described by $\pi(a, \gamma, \omega)$ where,

$$
\pi(a, \gamma, \omega)= \begin{cases}0 & \text { if } a=0 \\ y & \text { if } a_{t}=1 \text { and a currency crisis occurs } \\ x_{L} & \text { if } a_{t}=1, \text { a currency crisis does not occur but the projects mostly fail } \\ x_{H} & \text { if } a_{t}=1, \text { a currency crisis does not occur and the projects mostly succeed }\end{cases}
$$

and $y \leq x_{L}<0<x_{H} \cdot{ }^{14}$ We assume that conditional on the state of the world, all the foreign banks that have provided credits receive the same payoff. ${ }^{15}$ In case of a currency crisis, the payoff to a foreign bank that has provided credit is negative $(y<0)$. When no currency crisis occurs, a bank's payoff is negative in case the projects mostly fail $\left(x_{L}<0\right)$ and positive in case the project mostly succeed $\left(x_{H}>0\right)$. Moreover, a currency crisis is worse than project failure $\left(y \leq x_{L}\right)$.

This model gives rise to three different types of externalities. First, there is an informational externality that is due to the fact that the banks' actions may reveal their signals, which are valuable because they provide useful information about the true state of the world. Second, there is a payoff externality that is caused by the fact that additional credits increase the probability of a currency crisis and therefore reduce the payoff of those banks who have already provided credit. Finally, a "business stealing effect" is present too. The fact that the number of credits is limited, together with the fact that each bank that provides credit expects a positive expected payoff imply that a bank that succeeds in approaching the country early, eliminates the profit opportunities of other banks who were slower to respond.

\section{Equilibrium}

Denote the set of all possible histories by $\mathcal{H}$. A (pure) strategy for the banks is a function $\sigma: \mathcal{H} \times\left\{s_{L}, s_{U}, s_{H}\right\} \rightarrow\{0,1\}$ that maps the observed history of previous banks' actions and

\footnotetext{
${ }^{14}$ Notice that the number of credits that the country has received by the end of the first stage of the game, $\gamma$, affects the probability that a financial crisis occurs.

${ }^{15}$ Thus we assume that when a currency crisis occurs, no foreign bank has priority over another, neither does there exists any effective collateral.
} 
a bank's own private signal into a decision about whether or not to provide $C$ credits. A belief is a function $\beta: \mathcal{H} \times\left\{s_{L}, s_{U}, s_{H}\right\} \rightarrow \bigcup_{\tau \geq 1} \Delta\left(s_{L}, s_{U}, s_{H}\right)^{\tau}$, where $\Delta\left(s_{L}, s_{U}, s_{H}\right)$ denotes the set of all probability distributions over $\left(s_{L}, s_{U}, s_{H}\right)$, that maps the observed history and a bank's own signal at any time $t$ into $t-1$ probability distributions (beliefs) over the signals observed by the $t-1$ banks that moved before it, respectively. With slight abuse of notation, we denote the strategy and belief of the bank that moves at time $t$ by $\sigma_{t}$ and $\beta_{t}$, respectively. We focus our attention on pure strategy perfect Bayesian equilibria (PBE) (see, e.g., Osborne and Rubinstein (1994)).

Definition. A profile of strategies and beliefs $\left\{\left(\sigma_{t}, \beta_{t}\right)\right\}_{t=1}^{\infty}$ is a perfect Bayesian equilibrium (PBE) of the game above, if (1) for every $t \in\{1,2, \ldots\}$, the strategy of the bank that moves at time $t$ maximizes its expected payoff given its beliefs about the signals of the previous banks and the other banks' strategies; and (2) whenever possible, beliefs are updated according to Bayes' rule.

We have the following proposition,

Proposition 1. (i) A pure strategy PBE exists;

(ii) in every pure strategy PBE, banks' strategies are non-decreasing in their signals; and, (iii) the first stage of the game ends in finite time.

Recall that there are two ways in which the first stage of the game may end. Either the first stage of the game ends because the maximum of $2 C$ credits has been provided; or it ends because no bank provides credit, regardless of its signal. In the latter case, the banks "herd" on declining credit. ${ }^{16}$ To see this, suppose that after some history $h_{t-1}$, bank $t$ declines to provide credit regardless of its signal. This implies that bank $t+1$ cannot learn anything from bank $t$ 's action and is thus in exactly the same situation as bank $t$. Consequently, bank $t+1$ will also refuse to invest regardless of its signal, and the same is true for all future banks. Because of these related phenomena of informational cascades and herding, where the available public information swamps the banks' private information and induces them to behave identically, the first stage of the game always ends in finite time in spite of the fact that there are no search or inspection costs.

\footnotetext{
${ }^{16}$ Banerjee (1992) and Bikhchandani et al. (1992) are the classic references on herding and informational cascades. Further references may be found in Neeman and Orosel (1999).
} 
The herding phenomenon can help explain the reason so many banks invest in the same particular country or region, whereas other, apparently similar, countries are overlooked. In our model this phenomenon takes the following form: with a high probability either it is the case that two foreign banks invest or no foreign bank invests. This is illustrated by the following example.

Example 1: Herding. Consider the following stochastic environment: $\operatorname{Pr}\left(\lambda_{L}\right)=\operatorname{Pr}\left(\lambda_{H}\right)=$ 0.5 , and $\operatorname{Pr}\left(\theta_{1}\right)=0.01, \operatorname{Pr}\left(\theta_{2}\right)=0.04$, and $\operatorname{Pr}\left(\theta_{3}\right)=0.95$. The distribution of signals conditional on $\lambda$ is given by $\operatorname{Pr}\left(s_{U}\right)=0.25, \operatorname{Pr}\left(s_{L} \mid \lambda_{L}\right)=\operatorname{Pr}\left(s_{H} \mid \lambda_{H}\right)=0.5$, and $\operatorname{Pr}\left(s_{H} \mid \lambda_{L}\right)=$ $\operatorname{Pr}\left(s_{L} \mid \lambda_{H}\right)=0.25$. That is, with probability $\frac{1}{2}$, the signal describes the true $\lambda$, with probability $\frac{1}{4}$ it is uninformative, and with probability $\frac{1}{4}$ it is misleading. Payoffs are assumed to be $y=-500, x_{L}=-420$, and $x_{H}=630$. It is possible to show that a perfect Bayesian equilibrium of this game exists where the probability that at the end of the first stage of the game exactly one bank has invested is only $1 / 32=0.03125$, whereas the probability that two banks have invested is $23 / 32=0.71875$ and the probability that no bank ever invests is $1 / 4=0.25$.

The next four examples demonstrate the richness of behavior that is consistent the notion of pure strategy perfect Bayesian equilibrium. The following example demonstrates that equilibria are not necessarily unique.

Example 2: Pure strategy PBEs are not necessarily unique. Consider the following stochastic environment: $\operatorname{Pr}\left(\lambda_{L}\right)=\operatorname{Pr}\left(\lambda_{H}\right)=0.5$, and $\operatorname{Pr}\left(\theta_{1}\right)=.05, \operatorname{Pr}\left(\theta_{2}\right)=0.25$, and $\operatorname{Pr}\left(\theta_{3}\right)=0.7$. The distribution of signals conditional on $\lambda$ and the payoffs are as in Example 1. It is possible to show that there exists a perfect Bayesian equilibrium where bank 1 invests if and only if $s_{1} \in\left\{s_{U}, s_{H}\right\}$, and if bank 1 has invested (i.e., after the history $h_{1}=1$ ) bank 2 invests if and only if $s_{2}=s_{H}$. However, there is also another perfect Bayesian equilibrium where bank 1 invests if and only if $s_{1}=s_{H}$, and if bank 1 has invested (i.e., after the history $h_{1}=1$ ) bank 2 invests if and only if $s_{2} \in\left\{s_{U}, s_{H}\right\}$.

The reason for the non-uniqueness is that in equilibrium, one of two banks has to act "aggressively", that is, invest after the uninformative signal, whereas the other bank has to act "cautiously," that is, invest only after the high signal. If the first bank acts cautiously, investment reveals that it has observed a high signal and that allows the second bank to act 
aggressively. Moreover, given that the second bank acts aggressively, the first bank is forced to act cautiously. On the other hand, if the first bank acts aggressively, the act of investment reveals less favorable information (as it reveals only that the first bank has observed either the high or the uninformative signal) and thus the second bank is forced to act cautiously.

If a foreign bank has already invested, a second bank will invest if and only if it expects a positive expected payoff from doing so. By assumption, every foreign bank that invests receives the same payoff. Therefore, unless the act of investment of the second bank is triggered by some additional information, the first bank to invest cannot be deterred from investment by the knowledge that it will be followed by another foreign bank that will invest after it. However, typically the act of investment is triggered by some additional information. This may give rise to a "first mover's curse" that may deter investment altogether. We demonstrate this in the following example,

Example 3: "First Mover's Curse" may prevent investment. Consider the same stochastic environment and distribution of signals conditional on $\lambda$ as in Example 2. Suppose that payoffs are given by $y=-600, x_{L}=-420$, and $x_{H}=630$. It is possible to verify that with these parameters, there exists a unique perfect Bayesian equilibrium. In this equilibrium no bank ever invests, regardless of its signal, in spite of the fact that $E\left[\pi(1, C, \omega) \mid s_{H}\right]=$ $60>0$.

We explain the fact that no bank provides credit in equilibrium in terms of what we refer to as the "first mover's curse." In the example, because $E\left[\pi(1,2 C, \omega) \mid s_{1}=s_{2}=s_{H}\right]=12$ and $E\left[\pi(1,2 C, \omega) \mid s_{1}=s_{H}, s_{2}=s_{U}\right]=-72$, if the first bank revealed it has observed a high signal, the second bank has an incentive to invest if and only if it has observed a high signal too. The payoffs in the example are such that $E\left[\pi(1, C, \omega) \mid s_{1}=s_{H}\right]=60$ and $E\left[\pi(1, C, \omega) \mid s_{1}=s_{U}\right]=-71.25$, so if the first bank knew that no other bank will ever invest after it, then it would like to invest if and only if it observed a high signal. Thus, investment of the first bank reveals that it has observed a high signal. Consequently, the second bank invests whenever the first bank invested and the second bank observed a high signal. Because of the payoff externality, this reduces the payoff of the first bank from 60 when no other bank invests to 12. But because the first bank's expected payoff conditional on its own high signal and on a low or uninformative signal of the second bank who does not invest is $E\left[\pi(1, C, \omega) \mid s_{1}=s_{H}, s_{2} \in\left\{s_{L}, s_{U}\right\}\right]=-15$, the first bank's expected payoff from investing after observation of the high signal is negative when it anticipates the behavior of 
the second bank (which will invest if and only if it observes a high signal). It is given by

$$
\begin{aligned}
& E\left[\pi(1, \gamma, \omega) \mid s_{1}=s_{H}\right] \\
= & \operatorname{Pr}\left(s_{2}=s_{H} \mid s_{1}=s_{H}\right) \cdot 12+\operatorname{Pr}\left(s_{2} \in\left\{s_{L}, s_{U}\right\} \mid s_{1}=s_{H}\right) \cdot(-15) \\
= & -3.75 .
\end{aligned}
$$

In a sense, the first mover's curse is reminiscent of the winner's curse in auctions. In both situations, the value of the object conditional on the private signal and other players' strategies is lower than the expected value of the object conditional on the private signal alone. ${ }^{17}$

The "perversity" of the first mover's curse described in the previous example may in turn give rise to a phenomenon were the arrival of unfavorable public information about the success of the project may deter future banks and therefore actually encourage investment of the first bank. We demonstrate this in the next example.

Example 4: Unfavorable public information may encourage investment. Consider the following stochastic environment: $\operatorname{Pr}\left(\lambda_{L}\right)=\operatorname{Pr}\left(\lambda_{H}\right)=0.5$. Suppose that before the public signal is realized, $\operatorname{Pr}\left(\theta_{1}\right)=0.25, \operatorname{Pr}\left(\theta_{2}\right)=0.15$, and $\operatorname{Pr}\left(\theta_{3}\right)=0.6$, and after the public signal is realized, all players' change their assessments to $\operatorname{Pr}\left(\theta_{1}\right)=0.3, \operatorname{Pr}\left(\theta_{2}\right)=0.2$, and $\operatorname{Pr}\left(\theta_{3}\right)=0.5$. That is, the probability of a currency crisis increases in the sense of first order stochastic dominance. The distribution of signals conditional on $\lambda$ is identical to what it was in the previous examples and is given by $\operatorname{Pr}\left(s_{U}\right)=0.25, \operatorname{Pr}\left(s_{L} \mid \lambda_{L}\right)=\operatorname{Pr}\left(s_{H} \mid \lambda_{H}\right)=0.5$, and $\operatorname{Pr}\left(s_{H} \mid \lambda_{L}\right)=\operatorname{Pr}\left(s_{L} \mid \lambda_{H}\right)=0.25$. Finally, payoffs are given by $y=-600, x_{L}=-420$, and $x_{H}=630$. The effect of the unfavorable public signal on investment behavior is that in the environment where it is not realized there exists a unique perfect Bayesian equilibrium in which no bank ever invests (as in Example 3). However, after the public information is revealed, it is possible to verify that there is a unique perfect Bayesian equilibrium in which bank 1 invests if and only if $s_{1}=s_{H}$, and no other bank ever invests. The reason for this "perverse" effect of public information is that it eliminates the incentive of the second bank to invest after it has observed a high signal and, in addition, has inferred that the first bank has observed a high signal as well. In other words, the unfavorable public information encourages investment because it eliminates the first mover's curse.

\footnotetext{
${ }^{17}$ See Neeman and Orosel (1999) for an analysis of the combined effect of herding and winner's curse.
} 
As in standard herding models, in the model considered here, only actions (as opposed to private signals) may be observed by future banks. However, one may think it plausible that once credit is provided, the details of the credit contract may reveal, perhaps even perfectly, the bank's private signal. Thus, a different model may be considered, one where when credit is given, the private signal is revealed, and when credit is denied, the private signal remains unobserved. ${ }^{18}$ The main difference between such an alternative model and ours is that in the former, it is possible to show that a unique equilibrium exists. All other results, especially those about the inefficiency of the equilibrium discussed in the next section, remain unchanged. Furthermore, in such an alternative model, the presence of the negative payoff externality implies that banks have an incentive to try to hide their private signals. It is precisely this incentive that motivates our assumption that the act of providing credit does not reveal a bank's private signal. The existence of this incentive is demonstrated in the next example.

Example 5: Incentives to hide the private signal. Consider the following stochastic environment: $\operatorname{Pr}\left(\lambda_{L}\right)=\operatorname{Pr}\left(\lambda_{H}\right)=0.5$, and $\operatorname{Pr}\left(\theta_{1}\right)=0.1, \operatorname{Pr}\left(\theta_{2}\right)=0.3$, and $\operatorname{Pr}\left(\theta_{3}\right)=0.6$. The distribution of signals conditional on $\lambda$ is identical to what it was in the previous examples. The payoffs are again given by $y=-600, x_{L}=-420$, and $x_{H}=630$. If investment reveals the signal perfectly, there is a unique perfect Bayesian equilibrium. In this equilibrium bank 1 invests if and only if $s_{1} \in\left\{s_{U}, s_{H}\right\}$; and if bank 1 has invested after observation of $s_{1}=s_{H}$ (thereby revealing, by assumption, that it has observed a high signal), bank 2 invests if and only if $s_{2}=s_{H}$. If only the actions can be observed, there is also a unique perfect Bayesian equilibrium. In this equilibrium bank 1 invests if and only if $s_{1} \in\left\{s_{U}, s_{H}\right\}$, and no other bank ever invests if bank 1 has invested. Conditional on $s_{1} \neq s_{H}$, the expected payoff of bank 1 is the same in both equilibria, but conditional on $s_{1}=s_{H}$ the expected payoff of bank 1 is 64.5 in the first equilibrium (where investment reveals that bank 1 has observed the high signal), but 192 in the second equilibrium (where only the actions can be observed). Obviously, bank 1 is better off in the second equilibrium and thus has an incentive to hide its private signal. Intuitively, because of the negative payoff externality the bank that invests first does not want other banks to invest after it. Thus, it has an incentive to hide a high signal realization. Since it cannot selectively hide a high signal realization but reveal an

\footnotetext{
${ }^{18}$ Chari and Kehoe (1999) describe such a model of herding and financial crisis. However, their model does not distinguish between an international currency crisis and a domestic financial crisis.
} 
uninformative signal realization, it is better off when its signal is not perfectly revealed by its action. ${ }^{19}$

\section{Efficiency}

In this section we show that the perfect Bayesian equilibria of the game are generally inefficient. Sometimes too little credit is provided (as in Example 3 above), but mostly, too many credits are provided too easily.

Let $W:\{0, C, 2 C\} \times \Omega \rightarrow \mathbb{R}$ describe the social welfare associated with supplying a total number of $\gamma \in\{0, C, 2 C\}$ credits when the state of the world is given by $\omega \in \Omega$. We assume that,

$$
W(\gamma, \omega)= \begin{cases}0 & \text { if no credits are provided } \\ Y_{1} & \text { if } C \text { credits are provided and a currency crisis occurs } \\ Y_{2} & \text { if } 2 C \text { credits are provided and a currency crisis occurs } \\ \frac{\gamma}{C} X_{L} & \text { if no currency crisis occurs but the projects mostly fail } \\ \frac{\gamma}{C} X_{H} & \text { if no currency crisis occurs and the projects mostly succeed }\end{cases}
$$

where $Y_{2} \leq Y_{1}<0$ and $X_{L}<0<X_{H}$. The assumption that $Y_{2} \leq Y_{1}$ reflects the fact that if more credits have been provided, more capital is lost once a currency crisis occurs. The fact that $X_{L}$ and $X_{H}$ are multiplied by $\gamma / C \in\{0,1,2\}$ is due to the fact that the number of credits provided affects the extent of both the losses and gains if a currency crisis does not occur. In addition, we assume that $E\left[W(2 C, \omega)-W(C, \omega) \mid \lambda_{L}\right]<0$. That is, conditional on project failure, social welfare decreases if a second bank invests. ${ }^{20}$

An example for a social welfare function that satisfies the restrictions above is the one where social welfare is proportional to the collective payoff to the foreign banks, or,

$$
W(\gamma, \omega)=K \frac{\gamma}{C} \pi(1, \gamma, \omega)
$$

\footnotetext{
${ }^{19} \mathrm{~A}$ frequent critique that is raised against herding models is that in many of these models agents have no reason to keep their private signals secret, whereas revealing their signals would increase efficiency. As the preceding example illustrates, this critique does not apply in our case since it is clearly not in a bank's interest to reveal truthfully its signal realization.

${ }^{20}$ Notice that this assumption is equivalent to the following inequality being satisfied. $E\left[W(2 C, \omega)-W(C, \omega) \mid \lambda_{L}\right]=\operatorname{Pr}\left(\theta_{1}\right)\left(Y_{2}-Y_{1}\right)+\operatorname{Pr}\left(\theta_{2}\right)\left(Y_{2}-X_{L}\right)+\operatorname{Pr}\left(\theta_{3}\right) X_{L}<0$. It can be immediately verified that the inequality is satisfied if $Y_{2} \leq X_{L}$ and $\operatorname{Pr}\left(\theta_{3}\right)>0$.
} 
for some constant $K>0$. Maximization of this particular social welfare function is equivalent to maximization of the foreign banks' total expected payoffs.

Consider a social planner who can prescribe (pure) strategies to the foreign banks. We define the second-best outcome to be one that a social planner who maximizes the social welfare function $W$ can implement under the information constraints of the model. That is, foreign banks' strategies may depend only on the observed history of actions and their own signals. Note that the second-best outcome may involve inefficient herding as banks herd on denying credit in spite of the fact that the (unknown) state of the world justifies the provision of additional credit and that collecting and revealing more signals (as opposed to actions) would indicate this. Strategies that induce the second-best outcome are called second-best strategies. A pure strategy PBE is constrained efficient if it induces the same expected social payoff as under the second-best outcome.

Example 6: Too many credits are provided too easily. Consider the following stochastic environment: $\operatorname{Pr}\left(\lambda_{L}\right)=0.25, \operatorname{Pr}\left(\lambda_{H}\right)=0.75, \operatorname{Pr}\left(\theta_{1}\right)=0.1, \operatorname{Pr}\left(\theta_{2}\right)=0.2$, and $\operatorname{Pr}\left(\theta_{3}\right)=0.7$. The distribution of signals conditional on the state of the world $\lambda$ is given by $\operatorname{Pr}\left(s_{U}\right)=0.25, \operatorname{Pr}\left(s_{L} \mid \lambda_{L}\right)=\operatorname{Pr}\left(s_{H} \mid \lambda_{H}\right)=0.75$, and $\operatorname{Pr}\left(s_{H} \mid \lambda_{L}\right)=\operatorname{Pr}\left(s_{L} \mid \lambda_{H}\right)=0$. That is, with probability $\frac{3}{4}$ the signal fully reveals whether the projects are mostly successful or not, and with probability $\frac{1}{4}$ it is uninformative. Suppose that payoffs to the foreign banks are given by $y=-500, x_{L}=-420, x_{H}=630$, and social welfare payoffs are given by $Y_{1}=-1000, Y_{2}=-2000, X_{L}=-840$, and $X_{H}=1260$. That is $W(\gamma, \omega)=2 \frac{\gamma}{C} \pi(1, \gamma, \omega)$, $\gamma \in\{0, C, 2 C\}$. It is possible to show that the following profile of strategies achieves secondbest optimality: (i) after any history $h_{t-1}$ such that no bank has ever invested yet, bank $t$ invests if and only if $s_{t}=s_{H}$; (ii) after any history $h_{t-1}$ such that bank $t-1$ is the first bank that invested, bank $t$ invests if and only if $s_{t} \in\left\{s_{U}, s_{H}\right\}$ (because the fact that bank $t-1$ invested reveals that it has observed the high signal $s_{H}$ to bank $t$ ). Notice that along the equilibrium path, since high and low signals are perfectly informative, the fact that bank $t-1$ observed the high signal implies that bank $t$ must observe either a high or an uninformative signal and will therefore invest with probability 1.

However, it is also possible to show that in this example every perfect Bayesian equilibrium has the following properties: bank 1 invests if and only if $s_{1} \in\left\{s_{U}, s_{H}\right\}$; bank 2 invests if and only if bank 1 has invested (i.e., $a_{1}=1$ ) and $s_{2} \in\left\{s_{U}, s_{H}\right\}$; and no other bank ever invests. Notice that when $\lambda=\lambda_{H}, 2 C$ credits are already provided by the second 
period, but that this may also happen when $\lambda=\lambda_{L}$ if both the first two banks observe the uninformative signal (with probability $\frac{1}{16}$ ). Moreover, when $\lambda=\lambda_{L}$, at least the first bank invests whenever it observes the uninformative signal (with probability $\frac{1}{4}$ ).

It is straightforward to see that the equilibrium strategies are different from the secondbest strategies and that credits are provided too easily in equilibrium relative to the secondbest. In particular, bank 1 and bank 2 both invest after the signal realization $s_{1}=s_{2}=s_{U}$, whereas according to the second-best optimal strategies neither of them should invest given these respective signals. To see the intuition, note that if $\lambda=\lambda_{H}$, a bank will observe the high signal $s_{H}$ with probability 1 in finite time, whereas no bank will ever observe the low signal $s_{L}$. Consequently, in order to achieve the efficient outcome no credits should be provided until a bank observes the high signal $s_{H} \cdot{ }^{21}$ In contrast, in any equilibrium a bank will invest whenever the expected payoff from doing so is positive and thus will invest, in the example, even after the uninformative signal $s_{U}$. Whereas efficiency requires collecting more information upon observation of the uninformative signal $s_{U}$, from a bank's perspective, collecting more information implies it relinquishes its profit opportunity to another bank.

The presence of the information externality implies that the problem of identifying the second-best strategies is a difficult one. Since there are three signals but only two actions, the banks' actions cannot always be made to reveal their signals. In addition, the social planner has only "two shots," since the first stage of the game ends after two banks have invested. Notice that with strategies that are monotone non-decreasing in the banks' signals, at most two high signal realizations can be detected, one through inference and one from direct observation, before the first stage of the game ends. ${ }^{22}$ When prescribing a strategy for, say, bank $t$, the social planner has to consider not only what the best action after the history $h_{t-1}$ and bank $t$ 's observed signal is, but also the informational content of bank $t$ 's

\footnotetext{
${ }^{21}$ As a consequence, the first stage of the game will never end, in this example, if the second-best optimal strategies are played and $\lambda=\lambda_{L}$, because in this case no bank will ever receive the signal $s_{H}$. But if we substitute $\operatorname{Pr}\left(s_{L} \mid \lambda_{H}\right)=\operatorname{Pr}\left(s_{H} \mid \lambda_{L}\right)=0$ by $\operatorname{Pr}\left(s_{L} \mid \lambda_{H}\right)=\operatorname{Pr}\left(s_{H} \mid \lambda_{L}\right)=\varepsilon$ for some small positive $\varepsilon$, we get second-best optimal strategies that are basically analogous. The main difference is that if no bank has invested for a certain number of periods, no bank will ever invest and the first stage of the game ends. Another possibility would be to introduce discounting or small inspection costs. Note that in both of these alternative models there is a small probability of making a "mistake" from the ex-post perspective.

${ }^{22}$ Detection of a high signal realization $s_{H}$ is possible if and only if the bank that invested first had the strategy to invest if and only if it observed $s_{H}$.
} 
action that can be used by future banks. As the next example demonstrates, sometimes, this informational externality may imply that second-best strategies are not even monotone non-decreasing in the banks' own signals.

Example 7: Second-best strategies need not be monotone non-decreasing in the banks' private signals. Consider the following stochastic environment: $\operatorname{Pr}\left(\lambda_{L}\right)=\frac{2}{3}$, $\operatorname{Pr}\left(\lambda_{H}\right)=\frac{1}{3}, \operatorname{Pr}\left(\theta_{1}\right)=0, \operatorname{Pr}\left(\theta_{2}\right)=0.5$, and $\operatorname{Pr}\left(\theta_{3}\right)=0.5$. The distribution of signals conditional on $\lambda$ is given by $\operatorname{Pr}\left(s_{L} \mid \lambda_{L}\right)=\operatorname{Pr}\left(s_{H} \mid \lambda_{H}\right)=\frac{2}{3}$, and $\operatorname{Pr}\left(s_{H} \mid \lambda_{L}\right)=\operatorname{Pr}\left(s_{L} \mid \lambda_{H}\right)=\frac{1}{3}$. That is, the probability of the uninformative signal is zero. A signal points to the true $\lambda$ with probability $\frac{2}{3}$, and is misleading with the complementary probability. Suppose that payoffs are given by $Y_{2}=-130, X_{L}=0, X_{H}=180 .^{23}$ Let $I$ denote information and $X$ the random variable with realizations $X_{L}$ and $X_{H}$. Thus $E(X \mid I)$ denotes the expected social payoff conditional on information $I$ and on the absence of a currency crisis. The following table depicts a selection of signal events (i.e., information $I$ ) in the first column, the associated conditional probabilities $\operatorname{Pr}\left(\lambda_{L} \mid I\right)$ and $\operatorname{Pr}\left(\lambda_{H} \mid I\right)$ in the second and third column, respectively, and the associated conditional expected payoff $E(X \mid I)$ in the fourth column.

\begin{tabular}{|c|c|c|c|}
\hline$I$ & $\operatorname{Pr}\left(\lambda_{L} \mid I\right)$ & $\operatorname{Pr}\left(\lambda_{H} \mid I\right)$ & $E(X \mid I)$ \\
$s_{H}$ & $\frac{1}{2}$ & $\frac{1}{2}$ & 90 \\
$s_{H} \wedge s_{H}$ & $\frac{1}{3}$ & $\frac{2}{3}$ & 120 \\
$s_{H} \wedge s_{H} \wedge s_{H}$ & $\frac{1}{5}$ & $\frac{4}{5}$ & 144 \\
\hline
\end{tabular}

These numbers imply that $E\left[W(2 C, \omega) \mid s_{1}=s_{2}=s_{H}\right]=-65+60=-5<0$, and $E\left[W(2 C, \omega) \mid s_{1}=s_{2}=s_{3}=s_{H}\right]=-65+72=7>0$. Since with monotone non-decreasing strategies at most two high signal realizations can be detected before the first stage of the game ends, such monotone non-decreasing strategies imply that (only) one bank invests, and thus give an expected social payoff of 60 . However, since it is always optimal that at least one bank invests, to prescribe monotone non-decreasing strategies is not optimal. Consider, in particular, the alternative policy that prescribes the following strategies: (i) if no bank has invested up to $t-1$, bank $t$ invests if and only if $s_{t}=s_{L}$; (ii) if one bank has invested before $t-1$, bank $t$ invests if and only if $s_{t}=s_{H}$ and, in addition, the expected marginal

\footnotetext{
${ }^{23}$ Notice that since $\operatorname{Pr}\left(\theta_{1}\right)=0$, the value of $Y_{1}$ is irrelevant. The fact that $X_{L}=0$ (which violates our assumptions about the social welfare function $W$ ), simplifies the calculations but is not necessary. The same result holds if $X_{L}<0$ and $\left|X_{L}\right|$ is small. Similarly, $\operatorname{Pr}\left(s_{U}\right)$ could be positive.
} 
payoff from doing so is positive, that is, $E\left[W(2 C, \omega)-W(C, \omega) \mid h_{t-1}, s_{t}=s_{H}\right]>0$. Since according to this policy, (a) with probability 1 at least one bank invests; and (b) with positive probability a second bank invests, in which case the marginal payoff from doing so is positive, the expected payoff from this policy is strictly larger than 60 .

It is important to note that although second-best strategies may not be monotone nondecreasing, it is unlikely that a social planner can succeed in prescribing such strategies to the banks. Under a profile of strategies that are not monotone non-decreasing a bank may be asked to provide credit if it observed an unfavorable signal, but is prevented from providing credit if it observed a more favorable signal. The reason why this may be optimal is that the bank is "sacrificed" so that the fact that it observed a particularly unfavorable signal becomes public information and, perhaps more importantly, it allows the social planner to "signal" the observation of a high signal when the bank declines to invest, allowing for a large number of high signals to be successively signaled in this way. It is unlikely that banks will agree to sacrifice themselves in this way, neither is it likely that any international body will agree to subsidize such sacrifice for all the moral hazard problems it would raise.

The possibility that the second-best strategies are not monotone non-decreasing prevents us from obtaining a full characterization of the second-best strategies and outcomes. We are however able to provide the following two results.

Proposition 2. Among all monotone non-decreasing strategies, the ones that maximize social welfare are such that bank $t$ invests if and only if less than $2 C$ credits have been provided so far, it observed the highest possible signal $s_{t}=s_{H}$, and its investment increases the expected social welfare conditional on the history and the observed signal $s_{t}=s_{H}$.

It follows that if the second-best strategies happen to be monotone non-decreasing, then they must coincide with the strategies described in the previous proposition. We are also able to identify a general set of situations where second-best strategies are monotone nondecreasing.

Proposition 3. Suppose that by some time $t$, either $C$ credits have already been given, or it has become clear that no more than $C$ credits will ever be given. Then, as of time $t+1$ onwards, second-best strategies are monotone non-decreasing. In the former case, until $2 C$ 
credits have been supplied the second-best strategies are given by

$$
\sigma^{*}\left(h_{\tau-1}, s_{\tau}\right)= \begin{cases}1 & \text { if } s_{\tau}=s_{H} \text { and } \\ & E\left[W(2 C, \omega)-W(C, \omega) \mid\left\{\left(\sigma_{j}, \beta_{j}\right)\right\}_{j=1}^{\tau-1}, h_{\tau-1}, s_{\tau}=s_{H}\right]>0 \\ 0 & \text { otherwise }\end{cases}
$$

for every $\tau=t+1, t+2, \ldots$ In the latter case, until $C$ credits have been supplied the second-best strategies are given by

$$
\sigma^{*}\left(h_{\tau-1}, s_{\tau}\right)= \begin{cases}1 & \text { if } s_{\tau}=s_{H} \text { and } E\left[W(C, \omega) \mid\left\{\left(\sigma_{j}, \beta_{j}\right)\right\}_{j=1}^{\tau-1}, h_{\tau-1}, s_{\tau}=s_{H}\right]>0 \\ 0 & \text { otherwise }\end{cases}
$$

for every $\tau=t+1, t+2, \ldots$ Furthermore, there exists a finite number $K$ such that in both cases, either $C$ additional credits are provided by time $t+K$, or the first stage of the game ends.

We note that the situation where by some time $t$ it becomes clear that no more than $C$ credits ought to be provided ${ }^{24}$ may be interpreted as one where investment is not very attractive to begin with, perhaps because the probability of a currency crisis is quite high.

Finally, we note that since by Proposition 1, PBE strategies are non-decreasing, a PBE may be constrained efficient only if banks provide credit only after they have observed the best possible signal $s=s_{H}$. However, while investing only after observing the best possible signal is necessary for efficiency, it is not sufficient. Even if banks provide credit only after observing the best possible signal, PBEs are still likely to be inefficient because the banks require in addition that their expected profits from providing credit are positive, whereas constrained efficiency requires that expected social welfare is increased. In particular, the second bank to invest does not take into account the negative payoff externality it imposes on the bank that has already invested. The difference between these two criteria is likely to imply the inefficiency of any PBE even if banks invest only after observing the best possible signal.

\section{Policy}

While socially efficient profiles of strategies may be identified, self-interested international banks will not follow the recommendations of a benevolent social planner unless it is optimal

\footnotetext{
${ }^{24}$ This may be the case if, for example, even when $\lambda=\lambda_{H}$ no more than $C$ credits ought to be provided.
} 
for them to do so. In this section we pose the question of whether there exists a "simple" policy that such a social planner may employ to increase social welfare. We assume that the social planner can only rely on taxes and subsidies on short-term foreign credits to induce or discourage investments. Specifically, we assume that at any time $t \geq 1$, the social planner can impose a tax $z_{t}=z\left(h_{t-1}\right)$ (or a subsidy when $z_{t}<0$ ), which may depend on the publicly observed history $h_{t-1}$ but not on the privately observed signals, on bank $t$ if it invests. Banks that do not invest cannot be taxed and receive no subsidies. ${ }^{25}$ We assume that the social planner is capable of committing to a tax scheme $z: \mathcal{H} \rightarrow \mathbb{R} .^{26}$ Given this limited set of instruments, can the planner achieve the second-best or at least improve upon the perfect Bayesian equilibrium?

It is important to note that a system of taxes and subsidies can only help in the implementation of bank strategies that are monotone non-decreasing in the banks' private signals. This follows from the fact that for any given $\operatorname{tax} z_{t}$, whenever the expected gain to bank $t$ from supplying credit after observing a signal $s_{t} \in\left\{s_{L}, s_{U}\right\}$ is positive, it is also positive when the bank observes the highest possible signal $s_{t}=s_{H}$. Or,

$$
\begin{aligned}
E[\pi(1, C, \omega) \mid & \left.\left\{\left(\sigma_{\tau}, \beta_{\tau}\right)\right\}_{\tau=1}^{\infty}, z, h_{t-1}, s_{t}=s^{\prime}\right]-z_{t}>0 \\
& \Longrightarrow E\left[\pi(1, C, \omega) \mid\left\{\left(\sigma_{\tau}, \beta_{\tau}\right)\right\}_{\tau=1}^{\infty}, z, h_{t-1}, s_{t}=s^{\prime \prime}\right]-z_{t}>0
\end{aligned}
$$

for every $s^{\prime \prime}>s^{\prime}$. This has the following implication. Define the third-best as the best outcome that can be achieved under the information constraints of the model and the additional constraint that only monotone non-decreasing strategies may be employed by the banks. We have the following proposition.

Proposition 4. The third-best outcome can be implemented through a sequence of (history dependent) taxes and subsidies.

We note that it may be perfectly rational to subsidize a "first wave" of foreign credits, but to tax a "second wave" (in order to prevent it). ${ }^{27}$ Furthermore, it is possible that because

\footnotetext{
${ }^{25}$ Exemptions from (future) income taxes and (partial) state guarantees for the credits are in many ways equivalent to a subsidy and are not analyzed separately.

${ }^{26}$ Notice that commitment should not be problematic in this context because it is always in the best interest of the planner to follow the announced tax scheme in order to achieve the second-best outcome.

${ }^{27}$ If the expected social benefit from investing exceeds the bank's expected profit sufficiently, it is rational to subsidize investments that would not occur otherwise. However, if a bank invests when implementing
} 
of the "first mover's curse" (Example 3), no bank may invest. As implied by Example 4, imposing high enough taxes on future banks may eliminate this first mover's curse. Thus, a tax on a "second wave" of investments may trigger a "first wave." In fact, it may be the case that while no investment will occur in equilibrium absent any taxes, the second-best (or third-best) requires that both the first and later investments are taxed. ${ }^{28}$

As we have seen in the previous section, under some circumstances, namely when the next $C$ credits to be provided are sure to be the last ones, monotone non-decreasing strategies achieve the second-best outcome (Proposition 3). In those circumstances a system of taxes and subsidies can therefore generate the second-best outcome because such a system can guarantee achieve that banks invest exactly when they observe a high signal and conditional on that signal the investment increases social welfare. As noted in the previous section, one particular such case is where the risk of a currency crisis is so "severe" that no more than $C$ credits ought to be provided.

\section{Conclusions}

The prevalence of currency crises in recent years gives rise to the question of who shares the greatest responsibility for their repeated occurrence. ${ }^{29}$ Some argue that bailout guarantees are the main culprits. Because of these bailout guarantees, creditors neglect to screen out those projects that do not deserve to be given credit, too much credit is given, and the likelihood that a currency crisis occurs increases. ${ }^{30}$ Others argue that the blame lies with the second-best (or third-best), it reveals a high signal (Proposition 2). This may in turn induce further investment that is not socially optimal and thus should be prevented by a tax.

${ }^{28}$ Taxing the second investment makes it unprofitable and thus eliminates the first mover's curse. Having achieved that, taxing the first investment as well may be necessary to prevent investment after observation of only the uninformative signal.

${ }^{29}$ Chang and Velasco (1999), for example, write "The recent literature offers no shortage of villains to blame for the financial crashes in Mexico, East Asia, Russia, and Brazil: corruption and cronyism, lack of transparency and imperfect democracy, misguided investment subsidies and loan guarantees, external deficits that are too large (or sometimes too small), fixed exchange rates that are maintained for too long (or abandoned too readily), poor financial regulation, excessive borrowing abroad - the list goes on and on." (p. 1). Note that although many different causes are listed, they all agree in that the blame is with the debtor countries.

${ }^{30}$ Schneider and Tornell (1999) identify a class of models in which government bailout guarantees and moral hazard in financial markets are responsible for currency crises. "Such distortions induce overinvestment in 
debtor countries who adopted "crony capitalism" methods when they industrialized or when they liberalized their economies. This, in turn, raises the question of how those countries which adopted crony capitalist methods succeed in obtaining credit, to which the answer is, again, because foreign lenders can count on being bailed out.

In light of this discussion, the general message of this paper may be interpreted as placing part of the blame on the international financial community as well. As we show, even if foreign banks cannot count on being bailed out, they still provide too many credits too easily which may precipitate the onset of financial crises. As we show in Section 5, a judicious "correction" of the incentives of these foreign banks through taxes and subsidies may in fact improve overall efficiency and reduce the likelihood that crises occur.

negative NPV projects, which creates a hidden fiscal deficit. Since such a deficit is unsustainable, a crisis is inevitable." (p. 4). They cite Corsetti, Pesenti and Roubini (1998), Krugman (1998) and McKinnon and Pill (1997) as examples for this class of models that stress bailout guarantees. In their own model, "bailout guarantees can be a chief culprit in making the economy vulnerable [to a crisis]." (p. 28). This literature implies that preventing foreign banks from being bailed out may eliminate the risk of a currency crises or at least reduce this risk significantly. 


\section{Appendix: Proofs}

Proof of Proposition 1. We first prove (ii), then (iii), then (i). Let $\gamma_{t}=\sum_{i=1}^{t} a_{i} C \in$ $\{0, C, 2 C\}$ denote the number of credits provided to the country by time $t$. For every $t, \gamma_{t}$ is a random variable whose realization depends on the banks strategies and on the realization of banks' signals.

We show that in every pure strategy PBE banks' strategies are monotone non-decreasing in their signals. The bank that moves at $t$ invests if and only if ${ }^{31}$

$$
\lim _{T \rightarrow \infty} E_{\gamma_{T}, \omega}\left[\pi\left(1, \gamma_{T}, \omega\right) \mid\left\{\left(\sigma_{\tau}, \beta_{\tau}\right)\right\}_{\tau=1}^{T}, h_{t-1}, s_{t}\right]>0
$$

Suppose there exists some PBE $\left\{\left(\sigma_{t}, \beta_{t}\right)\right\}_{t=1}^{\infty}$ where for some time $t$ and some history $h_{t-1}$, the bank that moves at $t$ invests after observing the signal $s^{\prime}$ but not after observing the better signal $s^{\prime \prime}$. Suppose that bank $t$ deviates and invests after observing the signal $t^{\prime \prime}$. Its expected payoff is

$$
\begin{aligned}
& \lim _{T \rightarrow \infty} E_{\gamma_{T}, \omega}\left[\pi\left(1, \gamma_{T}, \omega\right) \mid\left\{\left(\sigma_{\tau}, \beta_{\tau}\right)\right\}_{\tau=1}^{T}, h_{t-1}, s^{\prime \prime}\right] \\
> & \lim _{T \rightarrow \infty} E_{\gamma_{T}, \omega}\left[\pi\left(1, \gamma_{T}, \omega\right) \mid\left\{\left(\sigma_{\tau}, \beta_{\tau}\right)\right\}_{\tau=1}^{T}, h_{t-1}, s^{\prime}\right] \\
> & 0 .
\end{aligned}
$$

The first inequality above follows from the fact that $s^{\prime \prime}$ is a better signal than $s^{\prime}$ implying a more favorable distribution over $\omega$ and the fact that the banks that move after bank $t$ cannot observe bank $t$ 's deviation and therefore do not change their behavior. The second inequality follows from the fact that $\left\{\left(\sigma_{t}, \beta_{t}\right)\right\}_{t=1}^{\infty}$ is a PBE. Therefore, bank $t$ should invest after observing the signal $s^{\prime \prime}$. A contradiction.

We now show that the first stage of the game ends in finite time. That is, there exists a time $T<\infty$ such that $\gamma_{t+1}=\gamma_{t}$ for every $t \geq T$. If after some history $h_{t}$, either two banks have already invested or no bank will invest in the future regardless of the signal it observes, then the first stage of the game has ended. Otherwise, since strategies are monotone non-decreasing, if after a history $h_{t-1}$ bank $t$ does not invest, it must be that the signal it observed, $s_{t}$, is either equal to $s_{L}$ or $s_{U}$, which increases the posterior probability that $\lambda=\lambda_{L}$

\footnotetext{
${ }^{31}$ Note that since $\pi$ is bounded from below and $E_{\gamma_{T}, \omega}\left[\pi\left(1, \gamma_{T}, \omega\right) \mid\left(\sigma_{\tau}\right)_{\tau=1}^{T}, h_{t-1}, s_{t}\right]$ is non-increasing in $T$, the limit exists.
} 
and thus decreases the expected payoff that future banks can obtain from investing. It can be verified that there exists a finite number $k$, such that the posterior expected payoff from investing conditional on observing $k$ bad or uninformative signals and one good signal is negative. Consequently, after $k$ banks decline to invest, no bank will want to invest and the first stage of the game will end.

Finally, existence of a pure strategy PBE follows from the fact that the first stage of the game ends in finite time. A pure strategy PBE exists by backwards induction.

\section{Proof of Propositions 2 and 3}

The three lemmas below are used in the proofs of Propositions 2 and 3.

Lemma 1. At any $t$, it is never second-best optimal to provide a credit independently of the signal $s_{t}$.

Proof. Fix a time $t$, a history $h_{t-1}$, and a profile of strategies $\left\{\sigma_{\tau}\right\}_{\tau=1}^{\infty}$. Suppose that under this profile of strategies, the bank that moves at $t$ provides $C$ credits regardless of the signal it observes. We distinguish between two cases: (1) $C$ credits have already been provided by time $t$, and (2) no credits have been provided by time $t$.

Consider case (1) first. Denote $r(\omega)=W(2 C, \omega)-W(C, \omega)$. Since $C$ credits have already been provided, providing $C$ more credits will end the first stage of the game yielding an additional social surplus of:

$$
\begin{aligned}
E\left[r(\omega) \mid\left\{\sigma_{\tau}\right\}_{\tau=1}^{t-1}, h_{t-1}\right]= & \operatorname{Pr}\left(\lambda_{L} \mid\left\{\sigma_{\tau}\right\}_{\tau=1}^{t-1}, h_{t-1}\right) E\left[r(\omega) \mid \lambda_{L}\right] \\
& +\operatorname{Pr}\left(\lambda_{H} \mid\left\{\sigma_{\tau}\right\}_{\tau=1}^{t-1}, h_{t-1}\right) E\left[r(\omega) \mid \lambda_{H}\right]
\end{aligned}
$$

Notice that, by assumption, $E\left[r(\omega) \mid \lambda_{L}\right]<0$. In case $E\left[r(\omega) \mid \lambda_{H}\right] \leq 0$ the conclusion follows immediately, so assume $E\left[r(\omega) \mid \lambda_{H}\right]>0$. Bayesian updating implies that, for every history $h_{t-1}$,

$$
\operatorname{Pr}\left(\lambda_{L} \mid\left\{\sigma_{\tau}\right\}_{\tau=1}^{t-1}, h_{t-1}, s_{t}=\cdots=s_{t+k}=s_{L}\right) \underset{k \nearrow \infty}{\nearrow} 1
$$

and

$$
\operatorname{Pr}\left(\lambda_{H} \mid\left\{\sigma_{\tau}\right\}_{\tau=1}^{t-1}, h_{t-1}, s_{t}=\cdots=s_{t+k}=s_{L}\right) \underset{k \succ \infty}{\searrow} 0 .
$$

Therefore, there exists a finite integer $K$ such that

$$
E\left[r(\omega) \mid\left\{\sigma_{\tau}\right\}_{\tau=1}^{t-1}, h_{t-1}, s_{t}=\cdots=s_{t+K}=s_{L}\right]<0
$$


By assumption, the profile of strategies $\left\{\sigma_{\tau}\right\}_{\tau=1}^{\infty}$ calls for the bank that moves at $t$ to provide credit regardless of its signal. We show that there exists another profile of strategies that generates a higher social surplus, implying that $\left\{\sigma_{\tau}\right\}_{\tau=1}^{\infty}$ cannot be second-best. Specifically, suppose that instead of providing $C$ credits at $t$ regardless of the signal and ending the first stage of the game, the banks follow the following strategies: every bank that moves at time $\tau \in\{t, \ldots, t+K\}$ provides credit if and only if it observes a signal $s_{\tau} \in\left\{s_{U}, s_{H}\right\}$. The banks that move after time $t+K$ do not provide credit regardless of their signal. We show that this new profile of strategies provides a higher expected social surplus than $\sigma=\left\{\sigma_{\tau}\right\}_{\tau=1}^{\infty}$. This follows from the fact that,

$$
\begin{aligned}
& E\left[r(\omega) \mid\left\{\sigma_{\tau}\right\}_{\tau=1}^{t-1}, h_{t-1}\right] \\
= & \operatorname{Pr}\left(s_{t}=\cdots=s_{t+K}=s_{L} \mid \sigma, h_{t-1}\right) E\left[r(\omega) \mid \sigma, h_{t-1}, s_{t}=\cdots=s_{t+K}=s_{L}\right] \\
& +\left(1-\operatorname{Pr}\left(s_{t}=\cdots=s_{t+K}=s_{L} \mid \sigma, h_{t-1}\right)\right) E\left[r(\omega) \mid \sigma, h_{t-1}, s_{\tau} \neq s_{L} \text { for some } \tau \in\{t, \ldots t+K\}\right] \\
< & \left(1-\operatorname{Pr}\left(s_{t}=\cdots=s_{t+K}=s_{L} \mid \sigma, h_{t-1}\right)\right) E\left[r(\omega) \mid \sigma, h_{t-1}, s_{\tau} \neq s_{L} \text { for some } \tau \in\{t, \ldots t+K\}\right]
\end{aligned}
$$

which is equal to the additional expected social surplus under the new profile of strategies since in contrast to what happens under $\left\{\sigma_{\tau}\right\}_{\tau=1}^{\infty}$, under the new strategies, no credit is provided when $s_{\tau}=s_{L}$ for all $\tau \in\{t, \ldots, t+K\}$.

Consider now case (2). Fix a time $t$, a history $h_{t-1}$, and a profile of strategies $\left\{\sigma_{\tau}\right\}_{\tau=1}^{\infty}$. Suppose that no credits have been provided up to time $t$, and that under this profile of strategies, the bank that moves at $t$ provides $C$ credits regardless of the signal it observes. Under any profile of second-best strategies the first stage of the game must end in finite time with positive probability. Thus, if the profile of strategies $\left\{\sigma_{\tau}\right\}_{\tau=1}^{\infty}$ is second-best optimal, there exists a $T$ such that with positive probability the first stage of the game ends by period $t+T$. Consider the alternative profile of strategies $\left\{\sigma_{\tau}^{\prime}\right\}_{\tau=1}^{\infty}$, which is defined as follows: (i) for $\tau \in\{1, \ldots, t-1\}, \sigma_{\tau}^{\prime} \equiv \sigma_{\tau}$, i.e., the alternative strategy is identical to the original strategy; (ii) the bank that moves at $t$ does not provide any credit regardless of the signal it observes; (iii) the banks $\tau \in\{t+1, \ldots, t+T\}$ follow their original strategies $\sigma_{\tau}$ as if bank $t$ has invested, until according to the original strategy profile the first stage of the game has ended or period $t+T$, whichever comes first; (iv) if according to the original strategy profile the first stage of the game ends with some bank $\tau \in\{t, \ldots, t+T\}$, bank $\tau+1$ invests regardless of the signal it observes and the first stage of the game ends thereafter; (v) finally, if according to the original strategy profile the first stage of the game has not ended by time $t+T$, bank $t+T+1$ 
invests regardless of the signal it observes, and $\sigma_{\tau+1}^{\prime} \equiv \sigma_{\tau}$ for all $\tau \geq t+T+2$. That is, after bank $t+T$ we "insert" an additional bank that invests regardless of its signal ("instead of" bank $t$ ) and this additional bank is ignored by the banks that move later and follow their original strategies. Notice that whenever under the original profile of strategies $\left\{\sigma_{\tau}\right\}_{\tau=1}^{\infty}$ the first stage of the game ends with a bank $\tau \in\{t, \ldots, t+T\}$, under the alternative strategy profile $\left\{\sigma_{\tau}^{\prime}\right\}_{\tau=1}^{\infty}$ it ends with bank $\tau+1$, without any difference in the public information obtained. Otherwise play continues identically with a "lag" of one period. Consequently, the expected social payoff is exactly the same under both profiles of strategies, $\left\{\sigma_{\tau}\right\}_{\tau=1}^{\infty}$ and $\left\{\sigma_{\tau}^{\prime}\right\}_{\tau=1}^{\infty}$. However, from the proof of case (1) it follows that whenever under the profile of strategies $\left\{\sigma_{\tau}^{\prime}\right\}_{\tau=1}^{\infty}$ the first stage of the game ends with some bank $\tau \in\{t+1, \ldots, t+T+1\}$, a strictly higher social payoff can be achieved by some alternative (third) profile of strategies. Since the event that under the profile of strategies $\left\{\sigma_{\tau}^{\prime}\right\}_{\tau=1}^{\infty}$ the first stage of the game ends with some bank $\tau \in\{t+1, \ldots, t+T+1\}$ has, by construction, a positive probability, this implies that the profile of strategies $\left\{\sigma_{\tau}^{\prime}\right\}_{\tau=1}^{\infty}$ does not achieve the second-best outcome. But then neither can the original profile of strategies $\left\{\sigma_{\tau}\right\}_{\tau=1}^{\infty}$ be optimal because it generates the same expected payoff as $\left\{\sigma_{\tau}^{\prime}\right\}_{\tau=1}^{\infty}$. A contradiction.

Lemma 2. After any history $h_{t-1}$, the following cannot be second-best strategies for bank $t$ : (i) $a_{t}=1$ if and only if $s^{t}=s_{U}$; and, (ii) $a_{t}=1$ if and only if $s^{t} \in\left\{s_{L}, s_{H}\right\}$.

Proof. Notice that the two investment strategies described above are not based on any favorable information and they do not transmit any valuable information into the future. They are thus equivalent to lotteries where $C$ credits are provided with a certain probability, regardless of the signal, and with the complementary probability no credit is given, regardless of the signal. It is then straightforward to see that the previous lemma can be extended to cover this case too.

Lemma 3. After any history $h_{t-1}$ such that the next $C$ credits to be provided will be the last ones (either because $C$ credits have already been provided, or whatever information is revealed in the future, efficiency requires that no more than $C$ credits be provided ${ }^{32}$ ), the second-best strategy of bank $\tau \geq t$ is monotone non-decreasing in its signal.

\footnotetext{
${ }^{32}$ This may be the case, for example, if even when it is known that $\lambda=\lambda_{H}$, efficiency implies that no more than $C$ credits ought to be provided.
} 
Proof. Assume the condition described in the statement of the lemma is satisfied from time $t$ onwards. By the previous two lemmas, it is enough to show that if for some $\tau \geq t$ a second-best strategy prescribes $a_{\tau}=1$ upon observation of $s_{\tau}=s_{L}$ it must also prescribe $a_{\tau}=1$ upon observation of $s_{\tau}=s_{H}$.

Let $\sigma=\left(\sigma_{1}, \sigma_{2}, \ldots\right)$ denote a profile of second-best strategies. Suppose that for some $\tau \geq t, \sigma_{\tau}\left(h_{\tau-1}, s_{L}\right)=1$ but $\sigma_{\tau}\left(h_{\tau-1}, s_{H}\right)=0$. We show that there exists another profile of strategies, denoted $\sigma^{\prime}$, that generates a strictly higher expected social surplus, implying a contradiction. The profile of strategies $\sigma^{\prime}$ is defined as follows: it coincides with $\sigma$ everywhere, except that $\sigma_{\tau}^{\prime}\left(h_{\tau-1}, s_{L}\right)=0$, and $\sigma_{\tau}^{\prime}\left(h_{\tau-1}, s_{H}\right)=1$. Let $P=E\left[W(\gamma, \omega) \mid \sigma, h_{t-1}\right]$ denote the expected social welfare under $\sigma$ conditional on $h_{t-1}$, and let $P^{\prime}=E\left[W(\gamma, \omega) \mid \sigma^{\prime}, h_{t-1}\right]$ denote the expected social welfare under $\sigma^{\prime}$ conditional on $h_{t-1}$. In these expectations, $\gamma$ denotes the random number of credits that are being supplied at the end of the first stage of the game conditional on the history $h_{t-1}$ and the strategy profile $\sigma$ and $\sigma^{\prime}$, respectively. Finally, let $\bar{\gamma}$ denote the maximum number of credits that may be given. That is, $\bar{\gamma}=2 C$ if $C$ credits have already been given by $t$, and $\bar{\gamma}=C$ if no credits have been given by $t$. Notice that with slight abuse of notation, $P$ can be written as,

$$
\begin{aligned}
P= & \operatorname{Pr}\left(s_{H} \mid \lambda_{L}\right) \operatorname{Pr}\left(\lambda_{L} \mid h_{t-1}\right) E\left[W(\gamma, \omega) \mid \sigma, \lambda_{L}\right] \\
& +\operatorname{Pr}\left(s_{U} \mid \lambda_{L}\right) \operatorname{Pr}\left(\lambda_{L} \mid h_{t-1}\right) E\left[W(\gamma, \omega) \mid \sigma, \lambda_{L}\right] \\
& +\operatorname{Pr}\left(s_{L} \mid \lambda_{L}\right) \operatorname{Pr}\left(\lambda_{L} \mid h_{t-1}\right) E\left[W(\bar{\gamma}, \omega) \mid \lambda_{L}\right] \\
& +\operatorname{Pr}\left(s_{H} \mid \lambda_{H}\right) \operatorname{Pr}\left(\lambda_{H} \mid h_{t-1}\right) E\left[W(\gamma, \omega) \mid \sigma, \lambda_{H}\right] \\
& +\operatorname{Pr}\left(s_{U} \mid \lambda_{H}\right) \operatorname{Pr}\left(\lambda_{H} \mid h_{t-1}\right) E\left[W(\gamma, \omega) \mid \sigma, \lambda_{H}\right] \\
& +\operatorname{Pr}\left(s_{L} \mid \lambda_{H}\right) \operatorname{Pr}\left(\lambda_{H} \mid h_{t-1}\right) E\left[W(\bar{\gamma}, \omega) \mid \lambda_{H}\right],
\end{aligned}
$$

and that $P^{\prime}$ can be written as,

$$
\begin{aligned}
P^{\prime}= & \operatorname{Pr}\left(s_{H} \mid \lambda_{L}\right) \operatorname{Pr}\left(\lambda_{L} \mid h_{t-1}\right) E\left[W(\bar{\gamma}, \omega) \mid \lambda_{L}\right] \\
& +\operatorname{Pr}\left(s_{U} \mid \lambda_{L}\right) \operatorname{Pr}\left(\lambda_{L} \mid h_{t-1}\right) E\left[W(\gamma, \omega) \mid \sigma, \lambda_{L}\right] \\
& +\operatorname{Pr}\left(s_{L} \mid \lambda_{L}\right) \operatorname{Pr}\left(\lambda_{L} \mid h_{t-1}\right) E\left[W(\gamma, \omega) \mid \sigma, \lambda_{L}\right] \\
& +\operatorname{Pr}\left(s_{H} \mid \lambda_{H}\right) \operatorname{Pr}\left(\lambda_{H} \mid h_{t-1}\right) E\left[W(\bar{\gamma}, \omega) \mid \lambda_{H}\right] \\
& +\operatorname{Pr}\left(s_{U} \mid \lambda_{H}\right) \operatorname{Pr}\left(\lambda_{H} \mid h_{t-1}\right) E\left[W(\gamma, \omega) \mid \sigma, \lambda_{H}\right] \\
& +\operatorname{Pr}\left(s_{L} \mid \lambda_{H}\right) \operatorname{Pr}\left(\lambda_{H} \mid h_{t-1}\right) E\left[W(\gamma, \omega) \mid \sigma, \lambda_{H}\right] .
\end{aligned}
$$


Consequently,

$$
\begin{aligned}
P^{\prime}-P= & {\left[\operatorname{Pr}\left(s_{H} \mid \lambda_{L}\right)-\operatorname{Pr}\left(s_{L} \mid \lambda_{L}\right)\right] \operatorname{Pr}\left(\lambda_{L} \mid h_{t-1}\right)\left\{E\left[W(\bar{\gamma}, \omega) \mid \lambda_{L}\right]-E\left[W(\gamma, \omega) \mid \sigma, \lambda_{L}\right]\right\} } \\
& +\left[\operatorname{Pr}\left(s_{H} \mid \lambda_{H}\right)-\operatorname{Pr}\left(s_{L} \mid \lambda_{H}\right)\right] \operatorname{Pr}\left(\lambda_{H} \mid h_{t-1}\right)\left\{E\left[W(\bar{\gamma}, \omega) \mid \lambda_{H}\right]-E\left[W(\gamma, \omega) \mid \sigma, \lambda_{H}\right]\right\}
\end{aligned}
$$

Observe that,

$$
E\left[W(\bar{\gamma}, \omega) \mid \lambda_{L}\right]-E\left[W(\gamma, \omega) \mid \sigma, \lambda_{L}\right] \leq 0
$$

because $\gamma \leq \bar{\gamma}$ and when $\lambda=\lambda_{L}$ it is better to provide as few credits as possible; and

$$
E\left[W(\bar{\gamma}, \omega) \mid \lambda_{H}\right]-E\left[W(\gamma, \omega) \mid \sigma, \lambda_{H}\right] \geq 0
$$

because $\gamma \leq \bar{\gamma}$ and when $\lambda=\lambda_{H}$ it is better to provide as many credits as possible. Furthermore, since it cannot be that under a second-best strategy, $C$ additional credits are provided after $t$ with probability 1 and hence the upper bound $\bar{\gamma}$ is always achieved, at least one of the two inequalities above must be strict. Finally, the fact that, by assumption, both $\operatorname{Pr}\left(s_{H} \mid \lambda_{L}\right)<\operatorname{Pr}\left(s_{L} \mid \lambda_{L}\right)$, and $\operatorname{Pr}\left(s_{H} \mid \lambda_{H}\right)>\operatorname{Pr}\left(s_{L} \mid \lambda_{H}\right)$, implies that $P^{\prime}>P$. A contradiction.

We prove Proposition 3 before 2.

Proof of Proposition 3. We prove the Proposition for the case where after some history $h_{t-1}$, it becomes known that no more than $C$ credits will ever be provided. The proof for the other case is analogous. Let $\sigma=\left(\sigma_{1}, \sigma_{2}, \ldots\right)$ denote a profile of second-best strategies. The previous three lemmas imply that we only have to show that there does not exist some $\tau \geq t$, where at $\tau$ a bank provides $C$ credits after observing the uninformative signal $s_{U}$. Suppose then that $\tau \geq t$ is the last bank that optimally provides $C$ credits upon observation of the uninformative signal $s_{U}$ under $\sigma$. By assumption, all the banks that move after $\tau$, provide credit only upon observation of the highest possible signal $s_{H}$, if at all. Such a last bank exists because the monotonicity of banks' optimal strategies implies that for all large enough $t$,

$$
E\left[W(C, \omega) \mid \sigma, a_{1}=\cdots=a_{t-1}=0, s_{t}=s_{U}\right] \leq 0
$$

and, it cannot be optimal for bank $t$ to provide credit in such circumstances. ${ }^{33}$

\footnotetext{
${ }^{33}$ Investment upon observation of the uninformative signal $s_{U}$ in spite of a non-positive payoff can only be optimal if it is important to "warn" future banks of the worst possible signal $s_{L}$ in the following way: If
} 
We show that a profile of strategies, denoted $\sigma^{\prime}$, that coincides with $\sigma$ up to $\tau-1$, and from $\tau$ onwards is identical to the one described in the statement of the proposition and where bank $\tau$ provides $C$ credits only upon observation of the highest possible signal $s_{H}$ generates a higher expected social welfare than $\sigma$. Let $K^{*}$ denote the smallest integer number such that the bank moving at $\tau+K^{*}+1$ would not provide $C$ credits (provided none were provided before) even if it observes the highest possible signal $s_{H}$ under $\sigma$. That is, $K^{*}$ is the smallest integer number such that

$$
\begin{aligned}
& E\left[W(C, \omega) \mid \sigma, h_{\tau-1}, a_{\tau}=\cdots=a_{\tau+K^{*}}=0, s_{\tau+K^{*}+1}=s_{H}\right] \\
= & E\left[W(C, \omega) \mid \sigma, h_{\tau-1}, s_{\tau}=s_{L}, s_{\tau+k} \in\left\{s_{L}, s_{U}\right\} \forall k \in\left\{1, \ldots, K^{*}\right\}, s_{\tau+K^{*}+1}=s_{H}\right] \\
\leq & 0 .
\end{aligned}
$$

Note that $K^{*} \geq 1 .^{34}$

We let $K^{\prime}$ denote the analog to $K^{*}$ under $\sigma^{\prime}$. That is, $K^{\prime}$ is the smallest integer such that,

$$
\begin{aligned}
& E\left[W(C, \omega) \mid \sigma^{\prime}, h_{\tau-1}, a_{\tau}=a_{\tau+1}=\cdots=a_{\tau+K^{\prime}}=0, s_{\tau+K^{\prime}+1}=s_{H}\right] \\
= & E\left[W(C, \omega) \mid \sigma^{\prime}, h_{\tau-1}, s_{\tau+k} \in\left\{s_{L}, s_{U}\right\} \forall k \in\left\{0, \ldots, K^{\prime}\right\}, s_{\tau+K^{\prime}+1}=s_{H}\right] \\
\leq & 0
\end{aligned}
$$

The difference between $K^{\prime}$ and $K^{*}$ is that in the definition of $K^{\prime}$, we condition on more favorable information, namely, the fact that no credit was provided at $\tau$ implies that $s_{\tau} \in$ $\left\{s_{L}, s_{U}\right\}$ as opposed to $s_{\tau}=s_{L}$ in the definition of $K^{*}$. It therefore must be the case that $K^{\prime} \geq K^{*} .^{35}$ Denote the expected social welfare under $\sigma$ by $P^{*}$. Notice that $P^{*}$ can be written as,

$$
\begin{aligned}
P^{*}= & {\left[\operatorname{Pr}\left(s_{U} \mid \lambda_{L}\right)+\operatorname{Pr}\left(s_{H} \mid \lambda_{L}\right)\right] \operatorname{Pr}\left(\lambda_{L} \mid h_{\tau-1}\right) E\left[W(C, \omega) \mid \lambda_{L}\right] } \\
& +\left[\operatorname{Pr}\left(s_{U} \mid \lambda_{H}\right)+\operatorname{Pr}\left(s_{H} \mid \lambda_{H}\right)\right] \operatorname{Pr}\left(\lambda_{H} \mid h_{\tau-1}\right) E\left[W(C, \omega) \mid \lambda_{H}\right]
\end{aligned}
$$

bank $t$ does not invest, it reveals that it observed the signal $s_{L}$ and this, in turn, conveys such "bad news" that no future bank should ever invest, regardless of its observed signal. However, since the signals $s_{H}$ and $s_{L}$ cancel each other, if a bank should not invest after the sequence $\left(s_{L}, s_{H}\right)$ it should also not invest after $s_{U}$ because the updated probabilities are identical.

${ }^{34} \mathrm{This}$ is due to the fact that by assumption, $E\left[W(1, \omega) \mid \sigma, h_{\tau-1}, s_{\tau}=s_{L}, s_{\tau+1}=s_{H}\right] \quad=$ $E\left[W(1, \omega) \mid \sigma, h_{\tau-1}, s_{\tau}=s_{U}\right]>0$.

${ }^{35}$ This can be verified algebraically. 


$$
\begin{aligned}
& +\operatorname{Pr}\left(s_{L} \mid \lambda_{L}\right)\left[1-\left[1-\operatorname{Pr}\left(s_{H} \mid \lambda_{L}\right)\right]^{K^{*}}\right] \operatorname{Pr}\left(\lambda_{L} \mid h_{\tau-1}\right) E\left[W(C, \omega) \mid \lambda_{L}\right] \\
& +\operatorname{Pr}\left(s_{L} \mid \lambda_{H}\right)\left[1-\left[1-\operatorname{Pr}\left(s_{H} \mid \lambda_{H}\right)\right]^{K^{*}}\right] \operatorname{Pr}\left(\lambda_{H} \mid h_{\tau-1}\right) E\left[W(C, \omega) \mid \lambda_{H}\right] .
\end{aligned}
$$

Similarly, denote the expected social welfare under $\sigma^{\prime}$ by $P^{\prime} . P^{\prime}$ can be written as,

$$
\begin{aligned}
P^{\prime}= & \operatorname{Pr}\left(s_{H} \mid \lambda_{L}\right) \operatorname{Pr}\left(\lambda_{L} \mid h_{\tau-1}\right) E\left[W(C, \omega) \mid \lambda_{L}\right] \\
& +\operatorname{Pr}\left(s_{H} \mid \lambda_{H}\right) \operatorname{Pr}\left(\lambda_{H} \mid h_{\tau-1}\right) E\left[W(C, \omega) \mid \lambda_{H}\right] \\
& +\left[\operatorname{Pr}\left(s_{L} \mid \lambda_{L}\right)+\operatorname{Pr}\left(s_{U} \mid \lambda_{L}\right)\right]\left[1-\left[1-\operatorname{Pr}\left(s_{H} \mid \lambda_{L}\right)\right]^{K^{\prime}}\right] \operatorname{Pr}\left(\lambda_{L} \mid h_{\tau-1}\right) E\left[W(C, \omega) \mid \lambda_{L}\right] \\
& +\left[\operatorname{Pr}\left(s_{L} \mid \lambda_{H}\right)+\operatorname{Pr}\left(s_{U} \mid \lambda_{H}\right)\right]\left[1-\left[1-\operatorname{Pr}\left(s_{H} \mid \lambda_{H}\right)\right]^{K^{\prime}}\right] \operatorname{Pr}\left(\lambda_{H} \mid h_{\tau-1}\right) E\left[W(C, \omega) \mid \lambda_{H}\right] \\
\geq & \operatorname{Pr}\left(s_{H} \mid \lambda_{L}\right) \operatorname{Pr}\left(\lambda_{L} \mid h_{\tau-1}\right) E\left[W(C, \omega) \mid \lambda_{L}\right] \\
& +\operatorname{Pr}\left(s_{H} \mid \lambda_{H}\right) \operatorname{Pr}\left(\lambda_{H} \mid h_{\tau-1}\right) E\left[W(C, \omega) \mid \lambda_{H}\right] \\
& +\left[\operatorname{Pr}\left(s_{L} \mid \lambda_{L}\right)+\operatorname{Pr}\left(s_{U} \mid \lambda_{L}\right)\right]\left[1-\left[1-\operatorname{Pr}\left(s_{H} \mid \lambda_{L}\right)\right]^{K^{*}}\right] \operatorname{Pr}\left(\lambda_{L} \mid h_{\tau-1}\right) E\left[W(C, \omega) \mid \lambda_{L}\right] \\
& +\left[\operatorname{Pr}\left(s_{L} \mid \lambda_{H}\right)+\operatorname{Pr}\left(s_{U} \mid \lambda_{H}\right)\right]\left[1-\left[1-\operatorname{Pr}\left(s_{H} \mid \lambda_{H}\right)\right]^{K^{*}}\right] \operatorname{Pr}\left(\lambda_{H} \mid h_{\tau-1}\right) E\left[W(C, \omega) \mid \lambda_{H}\right]
\end{aligned}
$$

because $K^{\prime} \geq K^{*}$ implies that when we substitute $K^{*}$ for $K^{\prime}$ in $P^{\prime}$ either we subtract some positive term(s) from $P^{\prime}$ (when $K^{\prime}>K^{*}$ ) or it makes no difference (when $\left.K^{\prime}=K^{*}\right) .{ }^{36}$ It follows that,

$$
\begin{aligned}
& P^{*}-P^{\prime} \\
\leq & \operatorname{Pr}\left(s_{U} \mid \lambda_{L}\right)\left[1-\operatorname{Pr}\left(s_{H} \mid \lambda_{L}\right)\right]^{K^{*}} \operatorname{Pr}\left(\lambda_{L} \mid h_{\tau-1}\right) E\left[W(C, \omega) \mid \lambda_{L}\right] \\
& +\operatorname{Pr}\left(s_{U} \mid \lambda_{H}\right)\left[1-\operatorname{Pr}\left(s_{H} \mid \lambda_{H}\right)\right]^{K^{*}} \operatorname{Pr}\left(\lambda_{H} \mid h_{\tau-1}\right) E\left[W(C, \omega) \mid \lambda_{H}\right] \\
= & \operatorname{Pr}\left(s_{U} \mid \lambda_{L}\right) E\left[W(C, \omega) \mid \sigma, h_{\tau-1}, s_{\tau}=s_{L}, s_{\tau+k} \in\left\{s_{L}, s_{U}\right\} \forall k \in\left\{1, \ldots, K^{*}\right\}, s_{\tau+K^{*}+1}=s_{H}\right] \\
\leq & 0 .
\end{aligned}
$$

because, by definition of $K^{*}$, the penultimate expression is non-positive. Furthermore, if $K^{\prime}>K^{*}$, the first inequality above is strict; and if $K^{\prime}=K^{*}$, the second inequality must be strict because

$$
\begin{aligned}
& E\left[W(C, \omega) \mid \sigma, h_{\tau-1}, s_{\tau}=s_{L}, s_{\tau+k} \in\left\{s_{L}, s_{U}\right\} \forall k \in\left\{1, \ldots, K^{*}\right\}, s_{\tau+K^{*}+1}=s_{H}\right] \\
< & E\left[W(C, \omega) \mid \sigma^{\prime}, h_{\tau-1}, s_{\tau+k} \in\left\{s_{L}, s_{U}\right\} \forall k \in\left\{0, \ldots, K^{\prime}\right\}, s_{\tau+K^{\prime}+1}=s_{H}\right],
\end{aligned}
$$

which by assumption is non-positive.

\footnotetext{
${ }^{36}$ In order to see this, recall that $P^{\prime}$ is a series of $K^{\prime}+1$ positive terms, where the $k$ 'th term is the probability that bank $\tau+k$ invests times the conditional expected welfare from this investment.
} 
The last sentence of in the statement of the Proposition follows from the fact that when strategies are monotone non-decreasing, there is a finite integer $K$ such that

$$
E\left[W(C, \omega) \mid \sigma^{\prime}, h_{\tau}, s_{\tau+k} \in\left\{s_{L}, s_{U}\right\} \text { for all } k \in\{1, \ldots, K-1\}, s_{\tau+K}=s_{H}\right] \leq 0 .
$$

Proof of Proposition 2. Suppose that $\sigma$ is a profile of optimal monotone non-decreasing strategies. Because of the previous three lemmas it is sufficient to show that it is impossible that $\sigma$ prescribes investment upon observation of an uninformative signal. Moreover, we need to consider only the case that is not covered by Proposition 3. Suppose then that after some history $h_{t-1}$ bank $t$ is the last to provide credit upon observation of an uninformative signal, that no credits have been provided before $t$, and that the history $h_{t-1}$ does not imply that at most $C$ credits will be provided. Such a last bank exists because, by monotonicity, failure to invest for a sufficiently long number of periods indicates that the probability of the state $\lambda=\lambda_{H}$ is so low that it discourages investment altogether.

For any $t \in\{1,2, \ldots\}$, let $V_{t}\left(\gamma_{t}, p_{t}\right)$ denote the expected social welfare from continuing to follow the optimal monotone non-decreasing strategy profile, conditional on the number of credits provided by time $t$, denoted $\gamma_{t}$, and the probability of the good state $\lambda=\lambda_{H}$, denoted $p_{t}$. Consider an alternative strategy profile, denoted $\sigma^{\prime}$, that is identical to $\sigma$ everywhere except that under $\sigma_{t}^{\prime}$ investment is made if and only if $s_{H}$ is observed and under $\sigma_{t+1}^{\prime}$ investment is made if and only if either $s_{H}$ or $s_{U}$ is observed. The idea of the proof is first to show that $\sigma$ and $\sigma^{\prime}$ generate the exact same expected social welfare, and then to argue that $\sigma^{\prime}$, and thus $\sigma$, cannot be optimal because, by Proposition 3, it is strictly suboptimal to provide credit upon observation of an uninformative signal when $C$ credits have already been provided.

The following Table 1 describes the expected social welfare under $\sigma$ as a function of all the possible signal realizations in $t$ and $t+1: 37$

\footnotetext{
${ }^{37}$ For the first two lines of Table 1 note that because (by assumption) the history $h_{t-1}$ does not imply that at most $C$ credits will be provided, the strategy $\sigma_{t+1}$ must prescribe bank $t+1$ to invest upon observation of a high signal, if bank $t$ has invested. For the line corresponding to $\left(s_{L}, s_{H}\right)$ note that the strategy $\sigma_{t+1}$ must prescribe bank $t+1$ to invest upon observation of a high signal, if bank $t$ has not invested, because it prescribes bank $t$ to invest upon observation of the non-informative signal $s_{U}$, and the information $I=\left\{s_{t}=s_{L}, s_{t+1}=s_{H}\right\}$ is equivalent to the information $s_{t}=s_{U}$.
} 


\begin{tabular}{|l|l|}
\hline$\left(s_{t}, s_{t+1}\right)$ & expected social welfare conditional on $\sigma$ and $h_{t+1}$ \\
\hline & \\
$\left(s_{H}, s_{H}\right)$ & $E\left[W(2 C, \omega) \mid h_{t-1}, s_{t} \in\left\{s_{U}, s_{H}\right\}, s_{t+1}=s_{H}\right]$ \\
$\left(s_{U}, s_{H}\right)$ & $E\left[W(2 C, \omega) \mid h_{t-1}, s_{t} \in\left\{s_{U}, s_{H}\right\}, s_{t+1}=s_{H}\right]$ \\
$\left(s_{H}, s_{U}\right)$ & $V\left[C, \operatorname{Pr}\left(\lambda_{H} \mid h_{t-1}, s_{t} \in\left\{s_{U}, s_{H}\right\}, s_{t+1} \in\left\{s_{L}, s_{U}\right\}\right)\right]$ \\
$\left(s_{L}, s_{H}\right)$ & $V\left[C, \operatorname{Pr}\left(\lambda_{H} \mid h_{t-1}, s_{t}=s_{L}, s_{t+1}=s_{H}\right)\right]$ \\
$\left(s_{H}, s_{L}\right)$ & $V\left[C, \operatorname{Pr}\left(\lambda_{H} \mid h_{t-1}, s_{t} \in\left\{s_{U}, s_{H}\right\}, s_{t+1} \in\left\{s_{L}, s_{U}\right\}\right)\right]$ \\
$\left(s_{U}, s_{U}\right)$ & $V\left[C, \operatorname{Pr}\left(\lambda_{H} \mid h_{t-1}, s_{t} \in\left\{s_{U}, s_{H}\right\}, s_{t+1} \in\left\{s_{L}, s_{U}\right\}\right)\right]$ \\
$\left(s_{L}, s_{U}\right)$ & $V\left[0, \operatorname{Pr}\left(\lambda_{H} \mid h_{t-1}, s_{t}=s_{L}, s_{t+1} \in\left\{s_{L}, s_{U}\right\}\right)\right]$ \\
$\left(s_{U}, s_{L}\right)$ & $V\left[C, \operatorname{Pr}\left(\lambda_{H} \mid h_{t-1}, s_{t} \in\left\{s_{U}, s_{H}\right\}, s_{t+1} \in\left\{s_{L}, s_{U}\right\}\right)\right]$ \\
$\left(s_{L}, s_{L}\right)$ & $V\left[0, \operatorname{Pr}\left(\lambda_{H} \mid h_{t-1}, s_{t}=s_{L}, s_{t+1} \in\left\{s_{L}, s_{U}\right\}\right)\right]$ \\
&
\end{tabular}

Table 1

Table 2 describes the expected social welfare under $\sigma^{\prime}$ as a function of all the possible signal realizations in $t$ and $t+1$ :

\begin{tabular}{|l|l|}
\hline$\left(s_{t}, s_{t+1}\right)$ & expected social welfare conditional on $\sigma^{\prime}$ and $h_{t+1}$ \\
\hline & \\
$\left(s_{H}, s_{H}\right)$ & $E\left[W(2 C, \omega) \mid h_{t-1}, s_{t}=s_{H}, s_{t+1} \in\left\{s_{U}, s_{H}\right\}\right]$ \\
$\left(s_{U}, s_{H}\right)$ & $V\left[C, \operatorname{Pr}\left(\lambda_{H} \mid h_{t-1}, s_{t} \in\left\{s_{L}, s_{U}\right\}, s_{t+1} \in\left\{s_{U}, s_{H}\right\}\right)\right]$ \\
$\left(s_{H}, s_{U}\right)$ & $E\left[W(2 C, \omega) \mid h_{t-1}, s_{t}=s_{H}, s_{t+1} \in\left\{s_{U}, s_{H}\right\}\right]$ \\
$\left(s_{L}, s_{H}\right)$ & $V\left[C, \operatorname{Pr}\left(\lambda_{H} \mid h_{t-1}, s_{t} \in\left\{s_{L}, s_{U}\right\}, s_{t+1} \in\left\{s_{U}, s_{H}\right\}\right)\right]$ \\
$\left(s_{H}, s_{L}\right)$ & $V\left[C, \operatorname{Pr}\left(\lambda_{H} \mid h_{t-1}, s_{t}=s_{H}, s_{t+1}=s_{L}\right)\right]$ \\
$\left(s_{U}, s_{U}\right)$ & $V\left[C, \operatorname{Pr}\left(\lambda_{H} \mid h_{t-1}, s_{t} \in\left\{s_{L}, s_{U}\right\}, s_{t+1} \in\left\{s_{U}, s_{H}\right\}\right)\right]$ \\
$\left(s_{L}, s_{U}\right)$ & $V\left[C, \operatorname{Pr}\left(\lambda_{H} \mid h_{t-1}, s_{t} \in\left\{s_{L}, s_{U}\right\}, s_{t+1} \in\left\{s_{U}, s_{H}\right\}\right)\right]$ \\
$\left(s_{U}, s_{L}\right)$ & $V\left[0, \operatorname{Pr}\left(\lambda_{H} \mid h_{t-1}, s_{t} \in\left\{s_{L}, s_{U}\right\}, s_{t+1}=s_{L}\right)\right]$ \\
$\left(s_{L}, s_{L}\right)$ & $V\left[0, \operatorname{Pr}\left(\lambda_{H} \mid h_{t-1}, s_{t} \in\left\{s_{L}, s_{U}\right\}, s_{t+1}=s_{L}\right)\right]$ \\
& \multicolumn{2}{|l}{} \\
\hline
\end{tabular}

Table 2

Tables 1 and 2 demonstrate that the expected social welfare under $\sigma$ and $\sigma^{\prime}$ is identical. This follows from the fact that (1) the probabilities of observing any sequence of signals is identical 
in both tables, and (2) the order in which the signals $s_{t}$ and $s_{t+1}$ are observed is irrelevant as of time $t+2$ and onwards. Thus, the rows that correspond to signals $\left(s_{t}, s_{t+1}\right)=\left(s_{i}, s_{j}\right)$, $s_{i}, s_{j} \in\left\{s_{L}, s_{U}, s_{H}\right\}$, in Table 1 yield the same value function as the rows that correspond to $\left(s_{t}, s_{t+1}\right)=\left(s_{j}, s_{i}\right)$ in Table 2 , respectively.

Proof of Proposition 4. The proof is straightforward. Banks should be taxed so that only those that have observed the highest possible signal will want to provide credit. The tax/subsidy can be further refined so that the banks' objective function coincides with social welfare. 


\section{References}

Banerjee, A. (1992) "A simple model of herd behavior," Quarterly Journal of Economics $107,797-817$.

Bikhchandani, S., D. Hirshleifer and I. Welch (1992) "A theory of fads, fashion, custom, and cultural change as informational cascades," Journal of Political Economy 100, 992-1026.

Chang , R. and A. Velasco (1998), "The Asian Liquidity Crisis," NBER Working Paper no. 6796.

Chang , R. and A. Velasco (1999) "Liquidity Crises in Emerging Markets: Theory and Policy," NBER Working Paper no. 7272.

Chari, V. V., and P. Kehoe (1999), "On the Robustness of Herds," Federal Reserve Bank of Minneapolis research department, mimeo, August 1999.

Corsetti, G., P. Pesenti, and N. Roubini (1998) "Paper Tigers," mimeo, New York University.

Furman, J. and J. E. Stiglitz (1998) "Economic Crises: evidence and insights from East Asia," Brookings Papers on Economic Activity 2:1998, 1-114.

Kaminsky, G., S. Lizondo, and C. M. Reinhart (1998) "Leading Indicators of Currency Crisis," IMF Staff Papers 45, 1-48.

Krugman, P. (1998) "Bubble, boom, Crash: Theoretical Notes on Asia's Crisis," Working paper, MIT.

Krugman, P. (1999) The Return of Depression Economics, New York: W. W. Norton.

Lindgren, C., G. Garcia, and M. Saal (1996), Banking Soundness and Macroeconomic Policy, Washington: International Monetary Fund.

Morris, S. and H. S. Shin (1998) "Unique equilibrium in a Model of Self-Fulfilling currency Attacks," American Economic Review 88, 587-597. 
Neeman, Z. and G. O. Orosel (1999), "Herding and the Winner's Curse in Markets with Sequential Bids," Journal of Economic Theory 85, 91-121.

Osborne, M. J. and A. Rubinstein (1994) A Course in Game Theory, MIT Press, Cambridge.

Rodrik, D. and A. Velasco (1999) "Short-term capital flows," NBER Working Paper no. 7364 .

Sachs, J., A. Tornell and A. Velasco (1996) "Financial Crises in Emerging Markets: The Lessons from 1995," Brookings Papers on Economic Activity 1:1996, 147-198.

Schneider, M. and A. Tornell (1999) "Lending booms and speculative Crisis," mimeo, July 1999.

Stiglitz, J. (1999) "Capital market liberalization, economic growth, and instability," mimeo, The World Bank.

Tornell, A. (1999) "Common Fundamentals in the Tequila and Asian Crises", NBER Working Paper no. 7139. 